This item was submitted to Loughborough's Research Repository by the author.

Items in Figshare are protected by copyright, with all rights reserved, unless otherwise indicated.

\title{
The rise of corporational determinism: Digital media corporations and narratives of media change
}

PLEASE CITE THE PUBLISHED VERSION

https://doi.org/10.1080/15295036.2019.1632469

\section{PUBLISHER}

Routledge (Taylor \& Francis)

VERSION

AM (Accepted Manuscript)

\section{PUBLISHER STATEMENT}

This is an Accepted Manuscript of an article published by Taylor \& Francis in Critical Studies in Media Communication on $8 \mathrm{Jul}$ 2019, available online: https://doi.org/10.1080/15295036.2019.1632469

\section{LICENCE}

CC BY-NC-ND 4.0

\section{REPOSITORY RECORD}

Natale, Simone, Paolo Bory, and Gabriele Balbi. 2019. "The Rise of Corporational Determinism: Digital Media Corporations and Narratives of Media Change”. Loughborough University. https://hdl.handle.net/2134/37979. 


\title{
The rise of corporational determinism: Digital media corporations and narratives of media change
}

\section{Simone Natale}

Centre for Research in Communication and Culture, Loughborough University, UK

\section{Paolo Bory, Gabriele Balbi}

Istituto Media e Giornalismo (IMeG), Università della Svizzera Italiana, Lugano, Switzerland

\begin{abstract}
This paper proposes a new theoretical concept, corporational determinism, to describe narratives by which digital media corporations are presented as the main or only agency informing sociotechnical change. It aims to unveil how digital media corporations employ such narratives to reinterpret the past of digital media, to underline their leading role in present societies, and to show their ability in predicting and shaping the future. Drawing on examples of digital media corporations such as Amazon, Apple, Facebook and Google, we argue that corporational determinism helps companies to market more effectively their products and to build stronger claims in support of their right to inform debates and decisions about the governance of digital technologies. Critical media scholarship should counteract the narratives of corporational determinism with more sophisticated approaches that underline the role of a wider range of actors in media change.
\end{abstract}

Keywords:

Digital corporations; digital revolution; media imaginary; corporate identity; narratives of media 
change.

\section{The rise of corporational determinism:}

\section{Digital media corporations and narratives of media change}

In an inspired book about the emergence of the myth of subliminal influence, Charles Acland (2012) has shown how vernacular narratives about media inform public perceptions and, as a consequence, our interactions with these technologies. One of the most persistent and influential of such narratives is technological determinism, which presents technologies as the primal or the only cause of social change (Smith \& Marx, 1994). Despite being widely criticised in academic forums, technological determinism often surfaces in discourses and discussions about the impact of media technologies (Leonardi \& Jackson, 2004; Jordan, 2008). In the 1990s, as the Web moved its first steps, technological determinism was one of the key narratives through which this new system and digital media in general were presented as revolutionary technologies destined to change our societies and the world (Flichy, 2007; Mosco, 1998). Early cyber-enthusiastic discourses strongly relied on deterministic narratives by which the technology was seen as the solution to a wide range of economic, political, and social issues (Bingham, 1996) or, conversely, as a negative force that opened up a range of potential problems (Brunton, 2013).

Although technological determinism remains a significant way through which the role of old and new media technologies is imagined and discussed in the contemporary age (Peters, 2017), this paper argues that a different but related form of determinism has become even more relevant in recent years. This discursive form, which we propose to describe as 'corporational 
determinism', ${ }^{1}$ presents digital media corporations as the main or the only agency informing broader societal change. As cyberutopian claims have become less dominant in public discourses about the Internet and digital media (Leggatt, 2017), and a small number of big corporations dominate the market for digital gadgets and Web-based services (Moore \& Tambini, 2018), corporational determinism provides a discursive resource that complements digital media corporations' market dominance. Pointing to a range of examples and drawing on literature in media studies, organisation studies, political economy, and corporate communication, this paper argues that digital companies such as Google, Apple, Facebook and Amazon have made substantial efforts to present themselves as leading the fabric of socio-technical development, thereby disregarding the complexities of media change and integrating popular histories of technology within their corporate identity and history. As a result, another powerful form of determinism has gained momentum, which appropriates the narrative trope of technological determinism and presents these corporations as the main drivers of social change.

The paper focuses mostly on four key companies operating in the digital market: Google, Apple, Facebook, and Amazon. In order to gain insight into the narratives constructed by these companies, we examined their promotional materials online, including their websites and mission statements, as well as a range of promotional messages produced by the companies including product launches and advertisements. The choice to select examples from these companies is due to two main reason. First, their status as leading digital platforms provides them with a key advantage in the political economy of the digital age, as Moore and Tambini (2018) have recently shown. ${ }^{2}$ Second, although companies in different economic sectors may construct and have constructed narratives of a similar kind, these corporations have been surprisingly successful in appropriating a range of popular narratives about the so-called "digital revolution," which became 
influential throughout the last three decades in contexts such as journalism, politics and, last but not least, academia (Streeter, 2010).

The ability of some of the biggest corporations in the digital media sector to control and make use of such narratives has very meaningful consequences: it helps these companies not only to market more effectively their products, but also to build stronger claims for their right to inform debates and decisions about the governance of digital technologies. Corporational determinism positions them as both an influential and a benevolent force, counteracting critical voices that point to their monopolistic strategies (Wu, 2011) and to the dangerous intertwining between platformization and media's political economies (Gorwa, 2019; van Dijck, Poell, \& de Waal, 2018). Presenting the agency of these corporations as a necessary condition for change, it suggests that their position of power is functional and necessary for technical and social innovation to take place, and thus minimizes the role of other important actors such as governments, smaller competitors, and users. The competition between these companies, as a consequence, happens at the financial and technological level as much as at the level of the imaginary and the public discourse. Similar to how they compete in the market and in digital platforms to acquire higher numbers of users and market share (Nieborg \& Helmond, 2019), these companies compete in the discursive sphere by offering and marketing themselves as key agents shaping the past, the present and the future of digital societies.

Scholars such as Siva Vaidhyanathan (2011), Christian Fuchs (2014), and Evgeny Morozov (2012), among others, have contributed to the emergence of critical approaches scrutinizing the action of big digital corporations such as Google, Apple, Amazon and Facebook. If economic, technical and legal factors that underpin the power of such corporations have been aptly examined, the role of discursive factors has been however the subject of less dedicated 
attention. This is an important gap because, rather than being neutral and inoffensive, the circulation of specific discourses and narratives in the public sphere may have practical implications and shape policy-making (Crawford, 2007; Mansell, 2011). Media policy, indeed, "is not a clean, administrative, depoliticized, and unproblematically evidence-based space but instead, an ideological power field in which certain preferences are confirmed and others marginalized" (Freedman, 2015), and recent studies in political economy have illuminated discursive formations underpinning public debates about the governance of digital technologies and their market (Pickard, 2014a; 2014b). These works confirm the importance of approaches that "listen in" (Maxwell, 2003) to power structures, in order to unveil the intertwining between power and discourses developed by the political and economic elites. This paper aims to contribute to these approaches by providing a theoretical and analytical resource for the study of the discursive formations through which digital media corporations construct positive arguments about their role in digital societies, with the potential to inform public debates and policies.

The paper is organised in three sections. The first section reviews approaches to determinism in scholarly discussions of media change to illuminate the relationship between corporational determinism, technological determinism, and other forms of determinism. The second section looks at literature in organisation studies and corporate communication addressing the role of narratives and storytelling in the construction of corporate identities. In the third section, we further develop the concept of corporational determinism through a range of examples of narratives constructed by the four leading digital corporations mentioned above. We argue that corporational determinism entails writing and rewriting narratives about the companies' capacity to shape the past, the present and the future. 


\section{From technological to corporational determinism}

In the philosophical tradition, determinism describes the idea "that everything can, in principle, be explained, or that everything that is, has a sufficient reason for being and being as it is, and not otherwise" (Hoefer, 2016). While determinism in philosophy has often been employed in reference to approaches that denies free will to humans, in the social sciences this notion has been employed more broadly as a form of critique against academic and popular theories that point to a single factor or variable as the key engine to explain change. Technological determinism, for instance, designates the tendency to represent technology as the sole or predominant cause for social change (Smith \& Marx, 1994). Conversely, the concept of social determinism has also been proposed to describe claims that emphasise sociological rather than technological factors (de la Cruz \& Lin, 2016), and recently, Srinivasan et al. (2017) referred to the notion that access to information can bring by itself social change as "information determinism."

Discussions on determinism in media studies have mainly revolved around technological determinism. From a sociological standpoint, technological determinism, and particularly the works of authors such as Marshall McLuhan and Harold Innis, have been accused of being monodimensional and dependent on Western culture (Edgerton, 2010); from a different perspective, historians of technology have called for the importance of taking into account numerous other factors determining change (MacKenzie, 1990: 386). Others, however, have pointed out that critiques of technological determinism tend to present it as "an unquestioned evil" (de Abreu, 2013: 268), without considering that under the umbrella of "technological determinism" lie different epistemological approaches that consider the role of technology in distinctly different ways (Grint \& Woolgar, 1997; Wyatt, 2008). 
The most effective and influential definition of technological determinism remains Raymond Williams' formulation, provided in his critique of Marshall McLuhan's work (Williams, 1974). Williams noted that McLuhan's (1964) approach tended to present technology as the only cause for social change, and therefore to downplay the relevance of many other causal factors that concur to direct change. However, as Jones (1998) aptly points out, Williams' goal was not to dismiss the technology as an important agent of history, but instead to underline the complex technological, social, and cultural nature of change. Jones emphasizes that Williams took seriously McLuhan's claim and he did not mean to understate the relevance of the technological per se. ${ }^{3}$ This contrasts with rigid readings of Williams' critique of McLuhan that tend to stress the dialectic between the two only in terms of opposition (Jones, 1998). Rather than directing his critique against technological determinism alone, Williams aimed to unveil the problematic nature of every approach offering a single cause to explain change - no matter if such overarching cause was technology, society, the agency of individuals or, we might add, of corporations.

Williams' argument, in this sense, should be read beyond the controversy against McLuhan and technological determinism, as a call to critically test all forms of determinism that identify a single variable informing social and technological processes. Proposing the concept of corporational determinism, in this sense, entails taking up Williams' incitation in order to critically assess deterministic approaches that present digital corporations as the sole or dominant agent of media change. Similar to Raymond Williams's critique of technological determinism, criticizing corporational determinism does not mean to dismiss the importance of corporations in informing social, cultural, economic and political processes. Corporations are indeed key actors in the contemporary media landscape; yet, their agency has to be understood in conjunction with a range of other social actors. 
There are also differences between technological and corporational determinism. Technological determinism tends to present a cause-and-effect narrative that poses technology as an immutable force of nature and erases human agency from the narrative. In contrast, corporational deterministic narratives may present the companies' agency also by giving emphasis to the agency of individuals such as their founders or CEOs. Their agency, however, is often 'naturalized' by pointing to a quasi-immanent desire that, according to these companies, characterize every single contribution and intervention of the corporation. As Tero Karppi (2018) has insightfully shown, for example, Facebook posits the idea of connection as the veritable foundation of the company, equating its efforts to extend its user base to a 'natural' tendency of society towards increased connectivity. Similarly, as shown by authors such as Peters (2015) and Vaidhyanathan (2011), Google presents itself as indistinguishable from the World Wide Web, thereby appropriating positive connotations embedded in the cyber-utopian and technological deterministic discourses, such as the Web's supposed capacity to inform wide changes towards more libertarian societal forms.

Within this process, the agency of individuals is programmatically incorporated within the self-representation of the company. The most evident example of this dynamics is the way in which Steve Jobs' biography has become indivisible from the history of Apple- as a result of precise narrative efforts by both Steve Jobs and Apple itself (Streeter, 2016). The same dynamic is evident also in media history before the digital age: there are many examples of huge media corporations named after the name of their founders, such as Bell, Marconi, Edison. Rather than affirming the role of individual invention in social change, such integrations of the human agency into the very core of the history and identity of the organization allows companies to use the mythical representation of inventors and entrepreneurs as a symbolic resource to confirm their social impact 
(Ortoleva, 1996). Additionally, corporational determinism obliterates the agency of users and their capacity to create competing narratives about their role in shaping the development and uses of new technologies.

The concept of technological determinism has not only been employed to criticize scholarly approaches to technological and media change, but also to describe popular narratives and myths that are used to support the interests and agendas of specific groups, assigning to technology a predominant role in shaping broad transformations and thereby presenting progressive and clear-cut visions about the future of technology and society (Doucet, 2018). Leonardi and Jackson (2004), for instance, document how leaders in high-tech organisations use narratives of technological determinism to invoke the 'inevitability' of technology and justify managerial decisions to the public. Tim Jordan (2008) and Johan Soderberg (2013) have focused on the example of hackers to show how beliefs about the impact of technology inform social behaviours in ways that may affect broader social and technological processes. Also, de Abreu (2013) points out that established narratives of technological determinism help individuals make sense of change and shape their understanding and imagination of the future, and Graham (1997) identifies technological determinism as one of the prevailing myths in debates about telecommunications.

These studies have drawn on technological determinism as an analytical lens to unveil how vernacular visions of media change are employed by specific groups in order to develop powerful narratives of media change that reinforce their own agenda, interests, and visions. In this regard, employing the concept of corporational determinism in a similar way as an analytical tool can help unveil how deterministic narratives are appropriated by corporate groups to achieve similar objectives. This responds to Doucet's (2018) suggestion that determinism represents a recurring 
narrative pattern that has been mobilized innumerable times in the history of media to the benefit of diverse agendas and subjects. While technological determinism is perhaps the most longstanding form of determinism in regard with media, corporational determinism adapts the narrative trope of determinism to the benefit of leading companies in the digital sector.

Rather than surpassing technological determinism and other popular narratives of media change, companies take possession, adapt and exploit existing narrative patterns, reinforcing the claim that they are able to realize the ultimate destiny of disruptive technologies such as the Web, computers, e-commerce, social media platforms, and many others. Thus, in order to understand corporational determinism, one needs to consider the key role of narratives in the construction of corporations' public image.

\section{Media narratives and corporate identities}

Studies in organisation and corporate communication have increasingly placed attention on the strategic process of identity construction in organisations through the use of media narratives (Zavyalova et al., 2017). Within organisation studies, research highlights the role of personal and collective identities in enforcing the internal functioning and the continuity of large organisations (Alvesson et al., 2008). Business and management scholars have unveiled how corporations' collective identities are strategically created and managed, and how they form the basis for the organisation's activities and outcomes (Boyce, 1996; Cornelissen et al., 2007). Narrative is one of the key ways through which such identities are constructed and reproduced. As argued by Vaara and Tienari (2011: 370), narratives provide means for making temporal sense of organisations, enabling a sense of continuity in their public image. Narratives are therefore keys to the establishment and the persistence of corporate reputation, which in turn informs corporations' 
capacity to convince customers and users that they are reliable suppliers of services and products (Vendelø, 1998).

Scholars have underlined the existence of alternative and competing narratives that make up organisations' identities. Narratives may exist in a dialogical or even in an oppositional relationship, as stories might be the subject of complex negotiation and conflict over meaning (Humphreys \& Brown, 2002; Vaara \& Tienari, 2011). This is also due to the fact that narratives are never fully under the control of the corporation, as other agents such as media, politicians, writers, competing companies and users contribute to the construction and dissemination of stories about corporations (Vaara et al., 2016). The meaning and the content of stories, moreover, change over time: as Michael S. Poulton (2005: 7) put it, “as one aspect of an organization's overall culture, stories begin and evolve over time as the organization develops through its lifecycle and as their ecologies change."

Yet, notwithstanding the intrinsic plurality of narratives, scholars have also noted that the representation of corporate identity within the public sphere is often characterized by a marked tendency towards simplification, as a limited range of narratives about corporations circulate through different channels and contexts and are repeated again and again - often under the careful scrutiny of the companies themselves. This has also to do with the fact that the circulation and dissemination of narratives within the public sphere tend to follow recurring patterns, relying on a logic of repetition that shapes their very possibility to become popular and widespread (Natale, 2016). Working within an organisation studies framework and focussing on the case study of the story about Steve Jobs' death, Wilner et al. (2014) refer to this process in Latourian terms as a "pasteurisation" of the narrative, by which "germs are eliminated in the name of a simple, rational 
and powerful explanation" (430). Through the pasteurisation of the narrative, elements that do not fit with the dominant narrative are disregarded, privileging a more coherent and stable narrative.

An apt example of how this works in practice can be found in the "genesis narratives" (Poulton, 2005) or "founding myths" (McWhinney \& Batista, 1988), i.e. the narratives about the foundation or the origins of an organisation. The construction of a genesis narrative or founding myth entails, in fact, a work of "pasteurisation" of the narrative through its reliance on recurring tropes. Founding myths as stories of origins often take the shape of recurring anecdotes: take, for instance, the anecdotes about the birth of companies in a garage, which recur in the mythology of several corporations (Godelier, 2007). Poulton highlights the importance of genesis narratives in the construction of an organisation's identity. As he notes, "where the narrative is particularly prevalent in organizational memory, the organization's culture is strong and more easily characterised" (2005: 7). A genesis narrative is in fact "the overriding, overarching story of an organization" (7) functioning like a metaphor through which the organisation describes itself.

\section{Shaping past, present and future: Corporational determinism in action}

Corporations employ resources and make specific efforts to stimulate the creation and circulation of narratives about their own development and contributions (Humphreys \& Brown, 2002; Vaara \& Tienari, 2011). While such narratives are manifold and serve different purposes, narratives of corporational determinism help companies to build stronger, more recognizable identities, to market more effectively their products, and to present themselves as central to wider social and technological changes. We propose here to distinguish between three types of deterministic narratives constructed and disseminated by digital media companies, according to their reliance on visions about the companies' agency in the past, the present, and the future. 


\section{Rewriting the past: when corporations become media historians}

The role of founding myths in the construction of group identities has been documented with regard not only to corporations, but to many other types of organisation or community. Myths of origins inform, for instance, the construction of national communities unified by a coherent narrative, which sometimes supports ideological and political agendas (Anderson, 1983; Hobsbawm, 1990). Also, religious confessions and sects may have founding myths in the form of narratives that help believers to enforce their sense of community and shared history (Rothstein, 2009). For what concerns corporational determinism, founding myths are an important way in which companies present themselves as key agents of media change. In fact, many digital media corporations have struggled to turn media history into a reservoir of metaphors for the construction of their identities, writing or re-writing the history of digital media in line with their own corporate narratives. If an organisation's founding myth becomes a metaphor for the organisation itself (Poulton, 2005), stories about how a medium came into being and developed turn into metaphors for the identity of a specific corporation. Offering the company's history as a metaphor for the emergence of media, in fact, reinforces the claim for its centrality in wider technological and social transformations.

Apple, for example, has built much of its external communication through the identification of the company with one of its founders and leaders, Steve Jobs (Streeter, 2016). In this case, it is by emphasizing the role of an individual that the company, embodied by the figure of its founder, occupies symbolically the very center of the innovation process. As Belk and Tumbat note, "the origin myth for the computer world and the digital forms of contemporary life rests heavily on the story of Steven Jobs and Stephen Wozniak creating the first Apple computer in Jobs' parents' 
garage" (Belk \& Tumbat, 2005: 208), despite the fact that the emergence of personal computers is a multifaceted and complex historical process that can not be attributed to single individuals or to a single company (Ceruzzi, 2003: 207-41). ${ }^{4}$ Steve Jobs, then, played a particular role in Apple's narratives. While leaders have often been relevant in digital media companies' communication strategies - think, for instance, of Bill Gates for Microsoft or, more recently, Elon Musk for Tesla -, the character of Steve Jobs has been even more clearly and systematically identified with his company. Following the trajectory of the hero's journey - which is, as Joseph Campbell famously pointed out, a key narrative pattern characterising a wide range of stories across different cultures and times (Campbell, 2004; see also Natale \& Bory, 2017) - the emphasis on Jobs can be regarded as a specific form of determinism in which the mythical figure of the leader embodies not only the corporation's identity, but also its attributes and qualities. The corporation is presented as capable to innovate, to "change everything," because it follows a specific system of values and behaviors synthetized in the story and the biographical path of its leader and founding father: a "hungry and foolish" man, able to innovate, think different, and stubbornly re-create and re-imagine the future (Streeter, 2016).

Not only the founding myth and the role of the mythological founder, but also other topical moments in the history of Apple have been presented by merging the company's history with media history. The launch of the Macintosh computer, for instance, was narrated by Apple through an explicit comparison with the introduction of the telephone that, according to the narrative, had entered so deeply into people's everyday life because it did not require specific competences to be used - as did by contrast the telegraph, which required the knowledge of Morse code to communicate. According to Jobs, the Macintosh was in this sense "the first 'telephone' or our industry" (Sheff, 1985: 10). As the telephone was able to simplify the use of telegraphic 
communication, making it available to everybody, so the Macintosh personal computer had changed computer history by turning complicated machines into user-friendly personal computers.

The equation of corporate history with media history also characterizes the external communication of Facebook, whose corporate narratives tend to equal its emergence with the introduction of social networks websites, even if other platforms were available before its appearance in 2004 (Ellison, 2007). A public letter to investors written by Zuckerberg in 2012 well exemplifies Facebook's approach. In the letter, Zuckerberg framed Facebook within the history of previous communication media:

“At Facebook, we're inspired by technologies that have revolutionized how people spread and consume information. We often talk about inventions like the printing press and the television - by simply making communication more efficient, they led to a complete transformation of many important parts of society. [...] Facebook aspires to build the services that give people the power to share and help them once again transform many of our core institutions and industries. By helping people form these connections, we hope to rewire the way people spread and consume information" (Zuckerberg, 2012).

As this example shows, the claim for the company's relevance in technological and social innovation is supported by a historical trajectory that places the company as the latest actor in a longer, teleological history through which ICTs have come to dominate symbolically and practically the world in which we live. Digital corporations, under this respect, can be considered revisionist "media historians" because they aim to (re)write the histories of digital media from 
their perspective in order to highlight their success and primacy in shaping technological and societal changes.

\section{Influencing the present: narratives of digital revolutions}

A further way in which digital media corporations are narrated as agents of change is by emphasizing their ability and power to shape the present. This happens, first, when corporations depict themselves as representatives of key social tendencies and phenomena characterizing contemporary societies; and second, when they present themselves as capable to respond to emerging social needs by changing the world with new and revolutionary ideas.

The case of Facebook is again exemplary in this regard. As Hoffman, Proferes and Zimmer (2016) have pointed out in their analysis of the rhetoric adopted by Mark Zuckerberg, the company represents itself as a key agent directing the development of contemporary society. They argue that "Zuckerberg creates a kind of cosmology that places the users, commercial actors, and Facebook shoulder to shoulder - a view that flattens and obfuscates the incomprehensibly large differences in power between these different players"; thereby, "Zuckerberg's discursive practices not only situates Facebook in society, but also situates society for Facebook" (Hoffmann, Proferes, \& Zimmer, 2018: 16). In order to promote a corporate image as open as possible, Facebook's institutional page insists on concepts such as the openness of hacker culture and counterculture not by chance, the same context in which the "digital revolution," according to established narratives (Turner, 2006), has taken shape. As written in the 2017's mission section of Facebook's website, "Facebook is defined by our hacker culture - an environment that rewards creative problem solving and rapid decision making" (Our mission, 2017). Breaking national boundaries and referring to a global audience, Facebook's corporate mission focuses on the concept of 
connectivity, both in its internal and public communication strategies. The main motto of the company, "To make the world more open and connected" (Hoffmann, Proferes, \& Zimmer, 2018: 16), is meant to stress that Facebook not only provides the essential infrastructure for social networking, but is more generally the provider of a global 'connectivity' between people. This suggests that corporational determinism is constructed not only through narratives, but also with the use of formal discursive patterns that are embedded in language and contribute to create implications of causality. Facebook, for instance, adopts a specific lexicon to highlight its direct agency on social and technological change: the company does not simply 'help' or 'facilitate' connectivity, but it "makes" the world connected, a choice of wording implying its primary role in the process. Similarly, when Apple claims that it is going to 'reinvent' the phone, it associates the company to the "great inventors" that are often presented as guiding the process of technological innovation. By employing the term 'reinvention', the company of Cupertino reinforces its claim to have triggered the 'revolution' of smart phones and mobile media (and before of other digital media).

The launch of new products is often the most adequate stage for digital media corporations to narrate and frame themselves as key agents in ongoing changes. These are in fact highly orchestrated performances that, when successful, become global events and attract vast audiences and attention (Mickalowski et al., 2008). The most notable example is Apple, whose successfully orchestrated launches of new products incessantly profited from the rhetoric of the digital revolution. The famous Macintosh 1984 TV advertisement, for instance, focused on the idea of revolution in its political sense. It depicted an Orwellian world where sedated individuals watch to their leader deliver a speech, while their submission is disrupted by the rebellion of a woman embodying Apple. As Sarah Stein has aptly shown in her analysis of the ad, the narrative of 
liberation and revolution was instrumental in placing the product within a broader cultural understanding of technological innovation. This ultimately served to offer the company to its potential customers as an engine of positive change (Stein, 2002). This narrative about the disruptive and constantly innovative "nature" of Apple characterizes the launch of many of its devices. In a key passage of his notorious 2007 launch event for the iPhone, for instance, Steve Jobs argued that Apple 'changed the whole computer industry' with the introduction of the first Macintosh in 1984, then it changed the way people listen to music as well as 'the entire music industry' with the introduction of the iPod in 2001, and finally, as already said, was about to 'reinvent the phone' with the iPhone itself (Jobs, 2007). In this way, the claim for the revolutionary potential of the company in the present was strictly connected to the use of media history that has been examined above. Apple re-narrates media history by placing itself at the centre of it and, at the same time, frames itself as the main provider of "new" personal devices, suggesting that both the company and the contemporary world live in a permanent state of digital innovation or better of digital revolution (Jobs, 2007; Magaudda, 2015; Sharma \& Grant, 2011).

\section{Creating the future: the myth of anticipation}

A third way in which corporational determinism emerges is when corporations construct narratives underlining their capacity to foresee and shape the future. Since at least the rise of the industrial revolution, as James Carey and John Quirk have shown in a now classic essay entitled "The History of the Future," visions of the future have underpinned the efforts of individuals and organisations to build optimistic narratives of progress and change. The future, they argue, has been 'a powerful political and cultural weapon' for the building of narratives of progress and redemption that revitalized optimism and dismissed dissent (Carey \& Quirk, 1989: 174). 
An apt example of how corporations employ visions of the future to build corporational deterministic narratives is Google's corporate communication. Google claims to be the main information provider, hence the container and the organizer of the Web itself (Vaidhyanathan, 2011). It presents itself as the 'perfect search engine' because it 'understands exactly what you mean and gives you back exactly what you want' (Our products, 2017). Yet, what the company proposes is much more than accurate personalization of search results: 'Even if you don't know exactly what you're looking for, finding an answer on the web is our problem, not yours. We try to anticipate needs not yet articulated by our global audience, and meet them with products and services that set new standards' (Ten things we know to be true, 2014). Pointing to its capacity for anticipation, Google posits the future as the veritable ending point of its deterministic narrative. Thus, for instance, the launch of Google Glass revolved around the claim that the company was actually anticipating and even building the future (Deshpande et al., 2013) - up to the point that even the commercial failure of this product was explained with the argument that Google was envisioning a future for which society was not ready (Curtis, 2015).

Scholars have shown that anticipation of the technological future is one of the key narratives spelled out by utopian discourses on the digital (Bødker, 2017; Streeter, 2010). Google's corporate narrative follows this pattern, depicting the image of an institution that aims to surpass well-established technologies such as the internet, smartphones and the World Wide Web in order to build an improved, mythical future. The company narrates itself as the chosen one - a benevolent, quasi-divine entity that shapes the ways in which society will live side by side with a new obsequious and personalized information provider. It is for this reason that John Durham Peters recently argued that Google's missionary ambition blurs at times with claims of divinity: 
'Google is a clergy defined by its control over the means of inscription and retrieval - as clergies and priesthoods always have been' (2015: 334).

The capacity to forecast and shape the future is also at the centre of corporational deterministic narratives constructed by another leading digital media company, Amazon. Amazon's founder and present CEO Jeff Bezos has often underlined such capacity as the defining characteristic of his company, pointing to the use of complex algorithms that anticipate users' tastes and behaviours (Stone, 2013). A telling example is a technology developed by the company and astutely named "anticipatory shipping," which employs algorithms that analyse previous behaviours of customers in order to forecast how many items will be shipped to specific locations in a given period - for instance, how many packages will be sent to the city of London in the week preceding Christmas. The system provides a competitive advantage to Amazon: it enables the company to prepare in advance, deploying the right numbers of vehicles and under-paid workers to deliver its parcels. Like other algorithm-based technologies, it also provides Amazon with a quasi-magical aura. Its capacity to anticipate behaviours suggests that Amazon (but this largely applies to Google, Apple and Facebook as well) does not only embody the future, but can also foresee it. Thus, the presentation of algorithms as anticipatory technology strengthens the corporations' claim to be actually shaping the future (Natale, 2019).

As these examples show, digital media companies often present themselves as the main agents of social change in the past, the present and even in the future. However, these three kinds of corporational deterministic narratives should not be seen as separated from each other. In corporational determinism, indeed, past, present and future are closely intertwined and allied: the claim that digital companies have driven technological change in the past is employed to support 
arguments about their ability to shape the present, as well as their missionary goal of shaping a better future.

\section{Conclusion: Why corporational determinism matters}

If certainly not the only, corporational determinism represents one of the main narratives about digital media that has emerged in the last decades, ignited by the rise of post-industrial societies since the 1970 s and most notably by the emergence of the Web since mid-1990s. Representing corporations as forces shaping the past, present and future of technology and society, corporational determinism informs perceptions and behaviours of consumers, stakeholders and policy makers, supporting the agendas of those corporations that have engaged in consistent efforts to create and disseminate these narratives. Reformulating an established narrative trope in media history that explains change through deterministic trajectories, corporational determinism presents these companies' dominance as inevitable, disregarding the fact that their power is also the fruit of political, economic, and social choices taken by different groups including governments, organisations, and users.

In Latin, the etymology of "de-terminare" means placing some self-evident limit to an object or space. This resonates with the fact that, as mentioned in the paragraph on the multifaceted scientific literature about corporative communication, the construction of effective messages conveying the identity of a company requires an act of 'pasteurisation' by which elements that do not fit within the dominant narrative are eliminated in order to delineate a coherent, stable, and official 'story'. Our analysis has shown that corporational determinism operates by limiting and defining narratives through three main dimensions: the incorporation of media histories into the companies' histories, the stated centrality of corporate actors in contemporary socio-technical 
innovations, and finally the tautological claim that these actors will continue to anticipate and shape the future.

Similar to the way in which technological determinism has served as a lens to recognize and illuminate how a particular category of narratives about media change is constructed and used, the concept of corporational determinism can serve as a theoretical tool for critical scholars to deconstruct, analyze, and contest how narratives placing digital corporations at the center of media change permeate societies. Proposing the notion of corporational determinism should thus serve as an incitation to critically reassess the centrality of digital media companies in public debates and representations of technological change. Companies such as Google, Amazon, Facebook and Apple, although extremely relevant in our time, are not to be presented as the only foundation of digital media landscapes. Indeed, contemporary societies are changed and shaped by digital corporations, but also and even more importantly by political decisions, cultural reconfigurations, macro-economic crisis, and social factors. Corporational determinism can result in disregarding other relevant trajectories in media change, including future scenarios in which the giants of today may disappear and be replaced by other actors.

This does not mean, however, that the role of corporations in media and social change is to be disregarded. Instead, corporational determinism should help critical scholars to interrogate the identity construction of digital media corporations alongside their impact in areas such as economy and labor, thereby acknowledging that the power structures of any organization develop at a material as well as at a discursive level ( Riad, 2005). It is by constructing alternative and competing discourses that critical theory has been able throughout its history to exercise significant impact on cultural, social, and economic debates regarding media and communications (Ott and Mack, 2010). And it is by offering a different narrative, based on a multidimensional perspective, 
that critical media studies will present an alternative view with the potential to shape the perspective and actions of regulators, stakeholders, social movements, and users. Such endeavor, however, needs to move from a deep understanding of how powerful mono-dimensional narratives are built and disseminated by digital media companies. This is an essential task that the concept of corporational determinism, as an additional analytical tool and a theoretical lens for critical media scholars, can help achieve.

\section{Acknowledgements}

We would like to thank Henrik Bødker, Fabio James Petani and the anonymous reviewers for providing exceedingly useful feedback upon earlier versions of this paper. 


\section{References}

Acland, C.R. (2007). Residual media. Minneapolis, MA: University of Minnesota Press.

Acland, C.R. (2012). Swift viewing: The popular life of subliminal influence. Durham, NC: Duke University Press.

Allen, D.S. (2005). Democracy, Inc.: The Press Law in the Corporate Rationalization of the Public Sphere. Champaign, IL: University of Illinois Press.

Alvesson, M., Lee Ashcraft, K., \& Thomas, R. (2008). Identity Matters: Reflections on the Construction of Identity Scholarship in Organization Studies. Organization, 15(1), 5-28.

Anderson, B. (1983). Imagined communities: Reflections on the origin and spread of nationalism. London, UK: Verso.

Audia, P.G., \& Rider, C.I. (2005). A garage and an idea: What more does an entrepreneur need? California Management Review, 48(1), 6-28.

Belk, R.W., \& Tumbat, G. (2005). The cult of Macintosh. Consumption Markets \& Culture, 8(3), $205-217$.

Bingham, N. (1996). Object-ions: From technological determinism towards geographies of relations. Environment and Planning D: Society and Space, 14(6), 635-657.

Boddy, W. (2004). New media and popular imagination: Launching radio, television, and digital media in the United States. Oxford, UK: Oxford University Press.

Bødker, H. (2017). Gadgets and Gurus: Wired magazine and innovation as a masculine lifestyle. Media History, 23(1), 67-79.

Boyce, M.E. (1996). Organizational story and storytelling: A critical review. Journal of Organizational Change Management, 9(5), 5-26.

Brunton, F. (2013). Spam: A shadow history of the Internet. Cambridge, MA: Mit Press. 
Butts, C. (2009). The Microsoft case 10 years later: Antitrust and new leading new economy firms. Northwestern Journal of Technology and Intellectual Property, 8(2), 275-291.

Campbell, J. (2004). The hero with a thousand faces. Princeton, NJ: Princeton University Press.

Carey, J.W., \& Quirk, J.J. (1989). The history of the future. In: Communication as culture:

Essays on media and society, Boston, MA: Unwin Hyman, pp. 173-200.

Ceruzzi, P.E. (2003). A history of modern computing. Cambridge, MA: MIT Press.

Cornelissen, J.P., Haslam, S.A., \& Balmer, J.M.T. (2007). Social identity, organizational identity and corporate identity: Towards an integrated understanding of processes, patternings and products. British Journal of Management, 18, 1-16.

Crawford, S. (2007). Internet think. Journal on Telecommunications and High Technology Law, 5, 467-486.

Curtis, S. (2015). Has Google Glass failed? The Telegraph. Retrieved from: http://www.telegraph.co.uk/technology/google/11350810/Has-Google-Glass-failed.html (accessed 7 May 2019).

de Abreu, M.J.A. (2013). Technological indeterminacy: Medium, threat, temporality. Anthropological Theory, 13(3), 267-284.

de la Cruz Paragas, F., \& Lin, T.T. (2016). Organizing and reframing technological determinism. New Media \& Society, 18(8), 1528-1546.

Deshpande, M.S., Uplenchwar, G., \& Chaudhari, D.N. (2013) Google Glass. International Journal of Scientific \& Engineering Research, 4(12), 1-4.

Doucet, E. (2018). In History, the future: Determinism in the early history of photography in France. Communication $+1,7(1), 4-19$.

Edgerton, D. (2010). Innovation, technology, or history: What is the historiography of 
technology about? Technology and Culture, 51(3), 680-697.

Ellison, N.B. (2007). Social network sites: Definition, history, and scholarship. Journal of Computer-Mediated Communication, 13(1), 210-230.

Flichy, P. (2007). The Internet Imaginaire. Cambridge, MA: MIT Press.

Freedman, D. (2015). Media policy fetishism. Critical Studies in Media Communication, 32(2), 96-111.

Fuchs, C. (2014). Social media: A critical introduction. London, UK: Sage.

Godelier, E. (2007). 'Do you have a garage?' Discussion of some myths about entrepreneurship. Business and Economic History Online, 5, 1-20.

Gorwa, R. (2019). What is platform governance? Information, Communication and Society, $22(6), 854-71$.

Graham, S. (1997). Telecommunications and the future of cities: Debunking the myths. Cities, $14(1), 21-29$.

Grint, K., \& Woolgar, S. (1997). The machine at work: Technology, work and organization. Cambridge, UK: Polity.

Hobsbawm, E.J. (1990). Nations and nationalism since 1780: Programme, myth, reality. Cambridge, UK: Cambridge University Press.

Hoefer, C. (2016). Causal Determinism. The Stanford Encyclopedia of Philosophy. Retrieved from: https://plato.stanford.edu/archives/spr2016/entries/determinism-causal/ (accessed 7 May 2019).

Hoffmann, A.L., Proferes, N., \& Zimmer, M. (2018). 'Making the world more open and connected ': Mark Zuckerberg and the discursive construction of Facebook and its users. New Media \& Society, 20(1), 199-218. 
Humphreys, M., \& Brown, A.D. (2002). Narratives of organizational identity and identification: A case study of hegemony and resistance. Organisation Studies, 23(3), 421-443.

Jobs, S. (2007) Keynote's Introduction of the iPhone at Mac World 2007. Retrieved from: https://thenextweb.com/apple/2015/09/09/genius-annotated-with-genius/ (accessed 27 June 2017).

Jones, P. (1998) The technology is not the cultural form?: Raymond Williams's sociological critique of Marshall McLuhan. Canadian Journal of Communication, 23(4), 7-24.

Jordan, T. (2008) Hacking: Digital media and technological determinism. Cambridge, UK: Polity.

Karppi, T. (2018). Disconnect: Facebook's Affective Bonds. Minneapolis, MA: University of Minnesota Press.

Kris, E., \& Kurz, O. (1979). Legend, myth, and magic in the image of the artist: A historical experiment. New Haven, CT: Yale University Press.

Leggatt, M. (2017). Cultural and political nostalgia in the age of terror: The melancholic sublime. London: Routledge.

Leonardi, P.M., \& Jackson, M.H. (2004). Technological determinism and discursive closure in organizational mergers. Journal of Organizational Change Management, 17(6), 615-631.

MacKenzie, D. (1990). Inventing Accuracy: A Historical Sociology of Nuclear Missile Guidance. Cambridge, MA: MIT Press.

Magaudda, P. (2015) Apple's Iconicity: Digital Society, Consumer Culture and the Iconic Power of Technology. Sociologica, 9(1), 1-15.

Mansell, R. (2012). Imagining the Internet: Communication, innovation, and governance. Oxford, UK: Oxford University Press. 
Maxwell, R. (2003). Herbert Schiller. Lanham: Rowman \& Littlefield.

Mazzucato, M. (2013). The entrepreneurial state: Debunking public vs. private sector myths. London, UK: Anthem Press.

McLuhan, M. (1964). Understanding media: The extensions of man. Toronto, CA: McGraw-Hill. McWhinney, W., \& Batista, J. (1988). How remythologizing can revitalize organizations. Organizational Dynamics, 17(2), 46-58.

Mickalowski, K., Mickelson, M., \& Keltgen, J. (2008). Apple's iPhone launch: A case study in effective marketing. The Business Review, 9(2), 283-288.

Moore, M., \& Tambini, D. (2018). Digital dominance: The power of Google, Amazon, Facebook, and Apple. Oxford, UK: Oxford University Press.

Morozov, E. (2012). Form and fortune: Steve Jobs's pursuit of perfection — and the consequences. The New Republic. Retrieved from: https://newrepublic.com/article/100978/form-fortune-steve-jobs-philosopher (Accessed 7 June 2019).

Morozov, E. (2017). Silicon Valley has been humbled. But its schemes are as dangerous as ever. The Guardian. Available from: https://www.theguardian.com/technology/2017/sep/02/silicon-valley-humbled-schemesdangerous (accessed 23 March 2018).

Mosco, V. (2004). The digital sublime: Myth, power, and cyberspace. Cambridge, MA: MIT Press.

Natale, S. (2016). Unveiling the biographies of media: On the role of narratives, anecdotes and storytelling in the construction of new media's histories. Communication Theory, 26(4), 431-449. 
Natale, S. (2019). Amazon can read your mind: A media archaeology of the algorithmic imaginary. In Natale, S. and Pasulka, D. (Eds.), Believing in bits: Digital media and the supernatural (pp. 19-36). Oxford, UK: Oxford University Press.

Natale, S., \& Bory, P. (2017). Constructing the biography of the Web: An Examination of the narratives and myths around the Web's history. In Brügger, N. (Ed.), Web 25: Histories from the First 25 Years of the World Wide Web (pp. 29-42). London: Peter Lang.

Nieborg, D. B., \& Helmond, A. (2019). The political economy of Facebook's platformization in the mobile ecosystem: Facebook Messenger as a platform instance. Media, Culture \& Society, 41(2), 196-218.

Ortoleva, P. (1996). Vite geniali: Sulle biografie aneddotiche degli inventori. Intersezioni, 1, 4161.

Ott, B.L., \& Mack, R.L. (2010) Critical media studies: An introduction. Chichester, UK: WileyBlackwell.

Our mission (2017). Retrieved from: https://newsroom.fb.com/company-info/ (accessed 27 June 2017).

Our Products (2017). Retrieved from: www.google.com/company/products (accessed 27 June 2017)

Park, D.W., Jankowski, N., \& Jones, S. (2011). The long history of new media: Technology, historiography, and contextualizing newness. New York, NY: Peter Lang.

Peters, J.D. (2015). The marvelous cloud: Towards a philosophy of elemental media. Chicago, IL: University of Chicago Press, 2015.

Peters, J.D. (2017). 'You mean my whole fallacy is wrong': On technological determinism. Representations, 140, 10-26. 
Pickard, V. (2014a). America's battle for media democracy: The triumph of corporate libertarianism and the future of media reform. Cambridge, UK: Cambridge University Press.

Pickard, V. (2014b). The great evasion: Confronting market failure in American media policy. Critical Studies in Media Communication, 31(2), 153-159.

Poulton, M.S. (2005). Organizational storytelling, ethics and morality: How stories frame limits of behavior in organizations. EJBO: Electronic Journal of Business Ethics and Organization Studies, 10(2), 4-9.

Riad, S. (2005). The power of 'organizational culture' as a discursive formation in merger integration. Organization Studies, 26(10), 1529-1554.

Rothstein, M. (2009). 'His name was Xenu. He used renegades...': Aspects of Scientology’s Founding Myth. In Lewis, J.R. (Ed.), Scientology (pp. 365-387). Oxford: Oxford University Press.

Sharma, A., \& Grant, D. (2011). Narrative, drama and charismatic leadership: The case of Apple's Steve Jobs. Leadership, 7(1), 3-26.

Smith, M.R., \& Marx, L. (1994). Does technology drive history?: The dilemma of technological determinism. Cambridge, MA: MIT Press.

Smyrnaios, N. (2017). Les GAFAM contre l'Internet. Une économie politique du numérique. Paris: INA.

Soderberg, J. (2013). Determining social change: The role of technological determinism in the collective action framing of hackers. New Media \& Society, 15(8), 1277-1293.

Srinivasan, J., Finn M., \& Ames, M. (2017). Information determinism: The consequences of the faith in information. The Information Society, 33(1), 13-22. 
Stein, S. (2002). The '1984' Macintosh ad: Cinematic icons and constitutive rhetoric in the launch of a new machine. Quarterly Journal of Speech, 88(2), 169-192.

Stone, B. (2013). The Everything Store: Jeff Bezos and the Age of Amazon. London, UK: Random House.

Streeter, T. (2010). The Net Effect: Romanticism, capitalism, and the internet. New York, NY: New York University Press.

Streeter, T. (2016). Steve Jobs, romantic individualism, and the desire for good capitalism. International Journal of Communication, 9, 3106-3124.

Ten things we know to be true (2014). Retrieved from: http://web.archive.org/web/20141028141849/http:/www.google.com/about/company/philos ophy (accessed 27 June 2017).

Turner, F. (2006). From counterculture to cyberculture: Stewart Brand, the Whole Earth Network, and the rise of digital utopianism. Chicago, IL: University of Chicago Press. Vaara, E., \& Tienari, J. (2011). On the narrative construction of multinational corporations: An antenarrative analysis of legitimation and resistance in a cross-border merger. Organization Science, 22(2), 370-390.

Vaara, E., Sonenshein, S., \& Boje, D. (2016). Narratives as sources of stability and change in organizations: Approaches and directions for future research. The Academy of Management Annals, 10(1), 495-560.

Vaidhyanathan, S. (2011). The Googlization of everything (and why we should worry). Berkeley, CA: University of California Press.

van Dijck, J., Poell, T., \& de Waal, M. (2018). The Platform Society: Public Values in a Connective World. Oxford, UK: Oxford University Press. 
Vendelø, M.T. (1998). Narrating corporate reputation: becoming legitimate through storytelling. International Studies of Management \& Organization, 28(3), 120-137.

Williams, R. (1974). Television: Technology and cultural form. London, UK: Fontana.

Wilner, A., Christopoulos, T.P., Alves, M.A., \& Vaz Guimarães, P.C. (2014). The death of Steve Jobs: How the media design fortune from misfortune. Culture and Organization, 20(5), $430-449$.

Wu, T. (2011). The master switch: The rise and fall of information empires. New York, NY: Vintage Books.

Wyatt, S. (2008). Technological determinism is dead: Long live technological determinism. In Hackett, E.J., Amsterdamska, O., \& Lynch, M. (Eds), The handbook of science and technology studies (pp. 165-180). Cambridge, MA: MIT Press.

Zavyalova, A., Pfarrer, M.D., \& Reger, R.K. (2017). Celebrity and infamy? The consequences of media narratives about organizational identity. Academy of Management Review, 42(3), $461-480$.

Zuckerberg, M. (2012). Mark Zuckerberg's letter to investors: 'The Hacker Way’. Retrieved from: https://www.wired.com/2012/02/zuck-letter/ (accessed 12 June 2017).

\section{Endnotes}

${ }^{1}$ We employ the adjective 'corporational' rather than the more widely used 'corporate' because the adjective 'corporate' (as in 'corporate communication') is usually employed to characterize narratives and messages that are produced by the corporations themselves, while the adjective 'corporational' conveys more appropriately the sense of a "discourse related to corporations." 
${ }^{2}$ It is not by chance that Google, Apple, Facebook and Amazon's initials coincide with the first four letters of the acronym GAFAM (M stands for Microsoft) used by journalists and scholars to summarize the so called 'giants' of the digital industry, thus the five most valuable listed firms in the world (Smyrnaios, 2017). An exhaustive list of digital corporations is hard to be provided and could also include, beside Microsoft, non-Western actors such as the Chinese JD, Alibaba, Tencent and Baidu or the Russian Yandex, Vk, Moi Mir, and Rutube.

${ }^{3}$ In this regard, Williams would probably have been sympathetic to John Durham Peters' recent call for acknowledging the usefulness of approaches that look specifically at the role of technology in media change, notwithstanding widespread critiques and debates about the fallacies of technological determinism (Peters, 2017).

${ }^{4}$ Despite its popularity, this anecdote might be at least in part apocryphal. According to one of the two protagonists of the story, Wozniak, the garage played in fact a marginal role in the events leading to the creation of the first Apple computer (Audia and Rider, 2005; Morozov, 2012). 